\title{
S6. The homeless, chronic mentally ill
}

\section{THE HOMELESS, CHRONIC MENTALLY ILL}

\section{Graham Thornicroft}

Director, PRiSM (Psychiatric Research in Service Measurement), Senior Lecturer, institute of Psychiatry, De Crespigny Park, London SE5 8AF, UK.

There is now consistent and worrying evidence from many developed countries that the occurrence of homelessness among the mentally ill is increasing. This paper will address the following issues:

- definitions of homelessness

- the proportion of known homeless populations who are mentaliy ill

- a critical evaluation of research methodologies used for these studies

- the diagnostic groups of such patients

- co-morbidity with alcohol, substance abuse, personality disorder, and physical illness

- homelessness among new long term and former old long stay groups

- evidence for effective service models for these patient groups

- the implications for mental health care and social / housing policy

\section{Mental Illness in Homeless People in Munich}

Manfred M. Fichter ${ }^{1)}$,Annette Greifenhagen ${ }^{2)}$, Manfred Koniarczyk ${ }^{3 \text { ' }}$

1) Psychiatrische Klinik der Ludwig Maximilians-Universität München \& Med. Psychosomatische Klinik Roseneck, Prien, Germany

2) Psychiatrische Klinik der Technischen Universität München, Germany

3) Bezirkskrankenhaus Haar, Haar, Germany

In a pilote study we have assessed a representative sample of 146 homeless males in the city of Munich. For case identification we used the Diagnostic Interview Schedule (DIS), a standardized interview developed for the use by trained lay interviewers. The interview also covered the context of the persons current live situation, the biography and social network. The same sampling and interview procedure as described by Koegel et al. (Archives of General Psychiatry, 1988; 45: 1085-92) for their study in Los Angeles was used. Therefore a direct comparison between the Los Angeles and the Munich sample is possible. Results indicate very high lifetime prevalence rates for mental disorders among homeless people living in Munich. Alcohol and drug abuse, affective and anxiety disorders and schizophrenia were disorders of high prevalence in our sample. There was also a high incidence of somatic disorders, such as tuberculosis, otherwise rare in developed countries. The results raise serious questions concerning the conceptualisation of appropriate health services, which meet the needs of the severely mentally ill homeless. In addition, basic needs. such as housing and employment should also be addressed. 
PSYCHIATRIC PROBLEMS AND CHRONIC MENTALLY ILL PERSONS AMONG HOMELESS AND MIGRANTS IN HUNGARY, WITH REFERENCE TO EFFORTS TO HELP THEM

Béla Buda, M.D. Alkotás st.48, Budapest 1123, Hungary

Homelessness and its equivalents have been there in Hungary also before 1989, the year of the change of political system, but in disguised and repressed forms. Homeless persons have been committed involuntarily to mental institution and sent to prison. Those who tried to escape this "solution" resorted to constant migration within the country and to ask for temporary residence in "workers' hostels" where a bed was provided in exchange for some menial works. The bulk of the homeless and migrants has been either chronically mentally ill or chronic alcoholic. After 1989 the issue of human rights has been taken more seriously so the problem of homelessness has become more visible. The increasing number of unemployed contributed to the growing mass of homeless. "Workers' hostels" have been closed and the rules of involuntary commitment have been defined more strictly, so many people have had to go to the streets, many of them chronic psychotics. Alcoholism has become rampant as well as criminality among the homeless. Efforts to help and support them have been made, such as the establishment of temporary homes, free food, drop in medical services, church and voluntary counselling, programmes to include psychiatric cases into treatment etc. Because of these efforts we have a lot of data about the pathways of becoming homeless, the nature and extent of psychopathology among them, the role of drugs and alcohol in the process of marginalization and alienation etc. Experiences with different homeless and ill groups are described in the paper, with special reference to treatment and social support given to them

SOCIAL CONDITIONS AND MENTAL ILLNESS AMONG HOMELESS PEOPLE IN COPENHAGEN

M Nordentoft. $N$ Wandall-Holm.

Psychiatric Department, Frederiksberg Hospital, University of Copenhagen, Denmark.

Purpose: The aim of this study is to evaluate social conditions and mental illness in a probability sample of homeless persons living in two large shelters in Copenhagen. In addition a sample of homeless living on the streets of Copenhagen will be described

Background: During the last decades, the number of psychiatric beds in Denmark has been reduced by more than one-half.

This development indicates that an increasing proportion of psychiatric patients live outside the psychiatric hospital, often with out-patient treatment and rather short periods of rehospitalization. It is more difficult to retain patients in such loosely structured forms of contact with psychiatric treatment. It is equally difficult for some patients to obtain and maintain residences of their own.

Design: A crossectional study of a probability sample of 200 homeless persons, representative for the group of 1200 persons using the two shelters in Copenhagen during a one year period. The 59 homeless living on the streets were interwieved in soup kitchens, drop-ins and public spaces, using "snowball-method" of contact.

Method: The homeless persons were interviewed with the diagnostic interview, Schedule of Clinical Assessment in Neuropsychiatry, and with a social interview concerning upbringing, social conditions, social integration, criminal history and previous psychiatric treatment.

Resuits: Among the homeless living on the street, two important groups could be distinguished: The severely mentally ill, mostly schizophrenics with grandios or persecution delusions. Both men and women were present in this group. The other group consisted of young men with alcohol or substance abuse, often a criminal record and a history of broken homes and childhood placement away from home.

In the shelters, 25 percent suffered from psychosis and two thirds of them were alcohol or drug abusers as well. 160 of 200 were alcohol or drug abuser, and 145 had a criminal record.

Preventive efforts will be discussed.
LONG INPATIENT STAY AS SUBSTITUTE OF OWN HOME. ANALYSIS BASED ON THREE CENSUSES COVERING ALL PSYCHIATRIC BEDS IN CZECH REPUBLIC IN 1968,1983 AND 1993. Ctirad ŚKODA, Pavel BAUDIŚ

Psychiatric Demography Unit, WHo Collaboration Center for Research and Training at Prague Psychiatric Center, CZ-181 03 Praha

Political and legal reasons explain why does homelessness emerge as a new societal phenomenon only after the velvet revolution. Before, the main substitute of own home were the health care and wellfare beds. To estimate the load imposed on heatth care by unsolved social problems of this kind the proportions of patients staying one year or longer without health care indication of the stay were determined in all mentat hospitals, psychiatric departments of general and teaching University hospitals by means of precoded census form with queries conceming the sex, age, duration of stay, diagnostic classification, employment status before last admission, mobility, physical status, participation in occupational therapy and rea-son of inpatient stay. Identical methodology was used in all three censuses. Follo wing changes were found 15 and 25 years after the initial census:

in-patients long-stay $(1+)$ expressed as

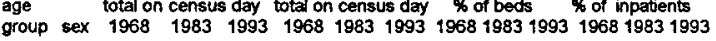

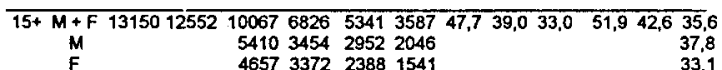

33,1

Reason of the stay (in \% of total) MEDICAL TREATMENT FORENSIC

Age SOCLAL INDICATED INDICATION

group Sex Year $196819831993 \quad 196819891993 \quad 196819831993$

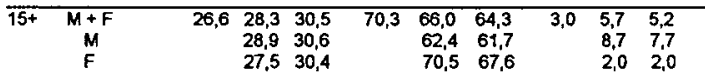

The needs of population aged $15+$ and staying one year and over could be classified as follows:

\begin{tabular}{|c|c|c|c|c|c|c|c|c|c|}
\hline Needs & 1968 & $\begin{array}{cc} & M \\
68 \quad 198\end{array}$ & $\begin{array}{ll}\text { lale } \\
83 \\
1993\end{array}$ & 1968 & $\begin{array}{c}\text { Fem } \\
81983\end{array}$ & 1993 & 1968 & $\begin{array}{r}M+ \\
1983\end{array}$ & 1993 \\
\hline $\begin{array}{l}\text { Biological treatment } \\
\text { Forensic indication } \\
\text { Vocational training } \\
\text { Somatic treatment } \\
\text { Social wellfare }\end{array}$ & $\begin{array}{r}8,0 \\
4,7 \\
33,7 \\
29,7 \\
23,9\end{array}$ & $\begin{array}{r}7,4 \\
8,3 \\
26,8 \\
33,0 \\
24,5\end{array}$ & $\begin{array}{c}10,5 \\
6,4 \\
20,5 \\
38,6 \\
24,1\end{array}$ & $\begin{array}{r}8,8 \\
0,6 \\
16,6 \\
35,0 \\
39,9\end{array}$ & $\begin{array}{r}8,8 \\
1,5 \\
11,3 \\
43,8 \\
34,6\end{array}$ & $\begin{aligned} 16,2 \\
1,6 \\
9,6 \\
45,6 \\
27,4\end{aligned}$ & $\begin{array}{r}8,4 \\
2,7 \\
25,3 \\
32,3 \\
31,3\end{array}$ & $\begin{array}{r}8,0 \\
5,3 \\
19,9 \\
37,8 \\
29,0\end{array}$ & $\begin{array}{r}12,9 \\
4,3 \\
15,8 \\
41,6 \\
25,4\end{array}$ \\
\hline
\end{tabular}

